\title{
Experimental Study on the Effect of Initial Temperature on CHF in a Vertical Annulus Narrow Channel with Bilateral Heated
}

\author{
M. Juarsa ${ }^{1,2^{*}}$, R.A. Koestoer ${ }^{1}$, N. Putra ${ }^{1}$, Indarto ${ }^{3}$ and S. Habsari ${ }^{4}$ \\ ${ }^{1}$ Department of Mechanical Engineering, Faculty of Engineering, University of Indonesia \\ Depok 16424, Jawa Barat, Indonesia \\ ${ }^{2}$ Center for Reactor Technology and Nuclear Safety, National Nuclear Energy Agency \\ Puspiptek Serpong, Tangerang - 15314, Indonesia \\ ${ }^{3}$ Department of Mechanical Engineering and Industry, Faculty of Engineering, Gadjah Mada University \\ Jl. Grafika No. 2 Campus UGM, Yogyakarta 55281, Indonesia \\ ${ }^{4}$ National Nuclear Regulatory Agency \\ Jl. Gajah Mada No. 8, Jakarta 10120, Indonesia
}

\section{ARTICLE INFO}

Article history:

Received 20 November 2010

Received in Revised form 25 July 2011

Accepted 08 August 2011

Keywords:

Bilateral

Boiling curve

CHF

Temperature

\begin{abstract}
A B S T R A C T
Study on understanding of the complexities of boiling in the narrow channel which was occured in a severe accident on nuclear power plant has been carried out in experimentally using simulation apparatus in order to achieve the safety management capability. Critical Heat Flux (CHF) is one important parameter to control heat during transient accident. The methodology of research is an experiment using experiment apparatus called HeaTiNG-01 test section with modifications in the outside pipe using stainless steel material as the reactor vessel wall simulation. Experiments were conducted by heating the heated rod as a simulation of debris until the desired initial temperature by bilateral heated. Then water with a saturation temperature in atmospheric was poured gravitationally into the narrow channel. Data acquisition system recorded temperature changes in transient during the cooling process. The transient temperature profile in double heating surface and rewetting point (rewet fronts) was characterized. Experiment was conducted at three initial temperature variations i.e. $650^{\circ} \mathrm{C}, 750^{\circ} \mathrm{C}$ and $850^{\circ} \mathrm{C}$ and using channel width $1 \mathrm{~mm}$. Experiment data was used to calculate heat flux then to fitting CHF form boiling curve. The results showed that CHF in outer pipe is higher than heated rod, these conditions explain that more heat is released through the outer pipe, so that the heat control can be done from outside the system to reduce the temperature quickly. The average value of CHF for each vertical position $100 \mathrm{~mm}$ and $400 \mathrm{~mm}$ at outer pipe are $380 \mathrm{~kW} / \mathrm{m}^{2}$ and $733 \mathrm{~kW} / \mathrm{m}^{2}$, and then at the heated rod are $250 \mathrm{~kW} / \mathrm{m}^{2}$ and $497 \mathrm{~kW} / \mathrm{m}^{2}$.
\end{abstract}

(C) 2011 Atom Indonesia. All rights reserved

\section{INTRODUCTION}

The accident of Three Mile Island unit 2 Nuclear Power Plant happened in June 1976, in Pennsylvania, USA becomes a most important accident in a civil nuclear reactor history. About half of the core melted (around 20 tons) and fell down into the lower plenum of the reactor pressure vessel (RPV). The molten core (so-called debris) was cooled down successfully and retained in the RPV without damaging the lower head vessel $[1,2]$. Figure 1 shows the last condition of the debris at the lower plenum. One of the mechanisms

\footnotetext{
* Corresponding author.

E-mail address: juars@batan.go.id
}

of heat removal from the debris was thought to be the formation of a narrow channel between the RPV lower head wall and the crust which was formed on the surface of the debris. The channel allowed remaining coolant to penetrate into the channel and to contribute heat removal from the molten core. To analyze the contribution of this channel cooling effect in the heat removal from the molten core, the heat transfer behaviour during cooling down of the hot surface in the narrow channel must be considered as an important parameter. The heat and mass transfer phenomena is rather complex. From this point of view, it is necessary to understand clearly the mechanism of the heat-transfer characteristics in the narrow channel. 


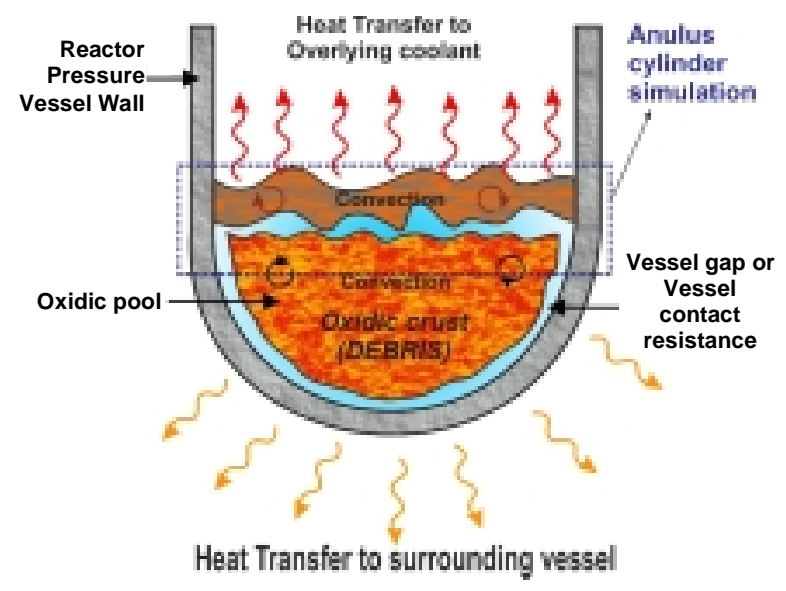

Fig.1. Concept of debris end-state configuration.

One of representative researches on the boiling heat-transfer characteristics of narrow channels was performed by Ishibashi and Nishikawa [3]. In their research, a remarkable effect of spatial restriction on the saturated boiling heat-transfer was reported. It was pointed out that in the saturated boiling heat-transfer in a narrow space, there was a coalesced bubble region having remarkably different characteristics beside the isolated bubble region, the heat transfer characteristics of which had already been confirmed. The channel width of the narrow space in which the effect of coalesced bubble is significant ranged from $0.5 \mathrm{~mm}$ to $2.0 \mathrm{~mm}$ at the atmospheric pressure condition. If the width of the narrow channel is larger than $2.0 \mathrm{~mm}$, the boiling region is isolated bubble region, while when the channel width is smaller than $0.5 \mathrm{~mm}$, the region is defined as liquid deficient region and the heat-transfer is much affected by the insufficient liquid supply, this situation was showed that counter current flow limitation (CCFL) become a significant cause. Recently, many experimental and theoretical researches on the heat-transfer during rewetting of hot vertical surfaces in narrow channel channels have been carried out [4 - 8]. It was pointed that different from the heat-transfer modes of heating process, during the cooling process, three heattransfer modes, i.e., film boiling (FB), transition boiling (TB) and nucleate boiling (NB) and two critical conditions, i.e., minimum film boiling (MFB) heat flux and critical heat flux (CHF) have some special characteristics. Monde [4] proposed a CHF correlation for natural circulation in a narrow space, and proved the coolability of the wall by penetrated water. Chang and Yao [5] also investigated $\mathrm{CHF}$ in narrow vertical annuli with a closed bottom for various fluids at different pressures and proposed CHF correlations based on the condition for CCFL. Ohtake [6] also performed quenching experiments. They pointed out that the heat-transfer characteristics during the rewetting were quite similar to those of conventional pool boiling. Murase [7] evaluated the effects of the superheat on the heat-transfer and CHF using existing experimental data and derived heat transfer correlations in a narrow channel. Tanaka et al. [8] also evaluated the CHF using Juarsa [9] experiment data on narrow channel. Besides those researches above cited, many experiments [10-13] on channel cooling have been performed and the heat-transfer models were proposed. Experimental data of annular flow have been obtained by many workers and numerous correlations have been developed [14-17]. However, most of these studies are based on data obtained from one-side heated cases. Su et al. [18] presented a theoretical model which describes the model of vertical upward annular flow in narrow annular channel with bilateral heating under low mass flow rate. However, the profiles of velocity in the liquid layers are linear due to that the number of calculation grids in liquid layers is not large enough when the model was numerically solved. It is obvious that the linear solution will departure from the true solution. Based on separated flow, Guanghui $\mathrm{Su}$ et al. [19] developed the prediction model for a theoretical three-fluids for annular upward flow in a vertical narrow annuli with bilateral. In his paper, the effects of outer wall heat flux on velocity and temperature in the inner liquid layer, thickness of inner liquid film and the inner wall heat transfer coefficient are very small; the similar effects of the inner wall heat flux are found and the critical heat flux (CHF) and critical quality are calculated. His work was based on S. Doerffer work whose examined the critical heat flux behaviour for annular flow in bilaterally heated annuli and compares it with that in tubes and unilaterally heated annuli from observation of experimental data [20]. In this paper, experimental study was conducted to investigate the effect of the variations of initial temperature of heated rod as CHF using HeaTiNG-01 test section which represents bilateral heated (double heating). Initial temperature for this experiment based on three variations of temperature, respectively are $650^{\circ} \mathrm{C}, 750^{\circ} \mathrm{C}$ and $850^{\circ} \mathrm{C}$ as a high wall superheat temperature. 


\section{EXPERIMENTAL METHODS}

\section{Experimental apparatus}

The main test section, which called as HeaTiNG-01, is a concentric annulus with a narrow channel of $1.0 \mathrm{~mm}$ as shown in Fig. 2. The inner rod is made of a SS316 pipe of $39 \mathrm{~mm}$ and $41 \mathrm{~mm}$ outer diameter (OD) also using SS316, for channel width $1,0 \mathrm{~mm}$ which $3 \mathrm{~mm}$ thickness. Inner rod has $750 \mathrm{~mm}$ of heated length and 14 sheathed thermocouples type K Alumel-Chromel installed $0.3 \mathrm{~mm}$ under the surface.

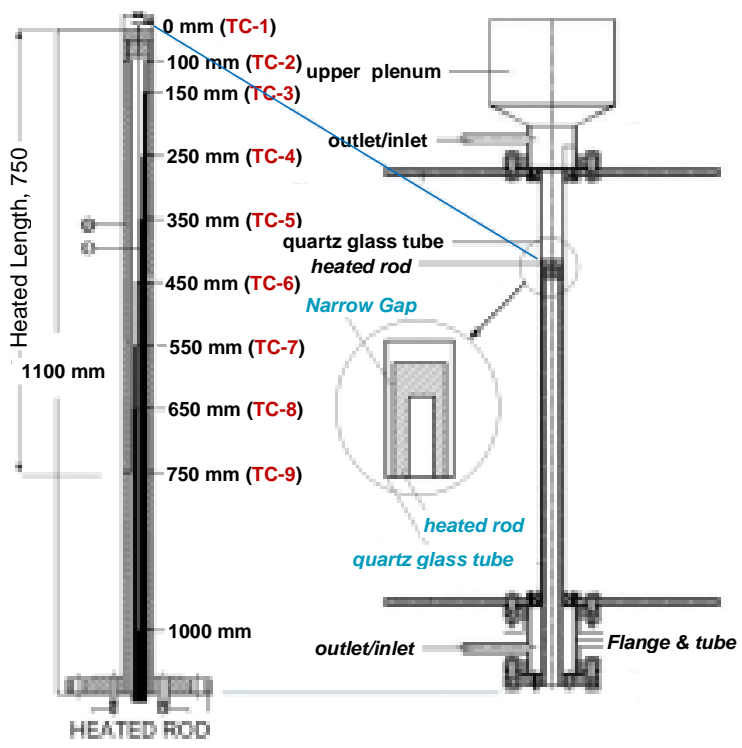

Fig. 2. Experimental Apparatus of HeaTiNG-01 Test Section.

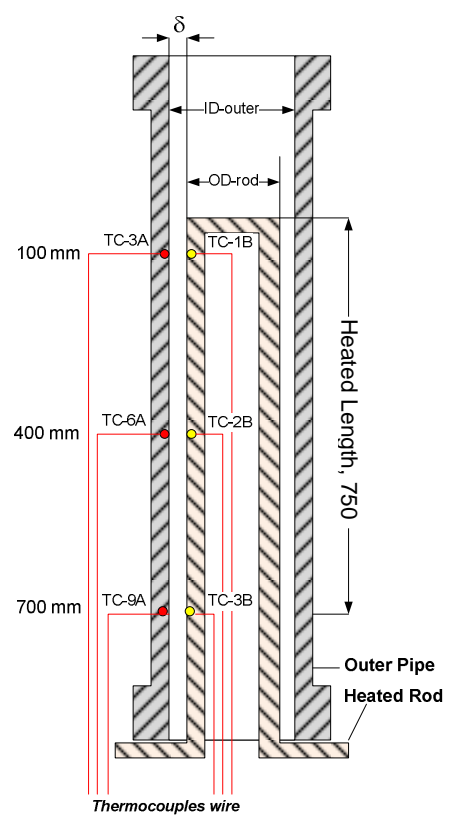

Fig. 3. Thermocouples position.
The outer pipe has three thermocouples which are installed in $0.5 \mathrm{~mm}$ from inner surface. In this experiment, eight thermocouples are used and located along the vertical position of the inner rod outer surface (TC-2, TC-3, TC-4, TC-5, TC-6, TC-7, TC-8 and TC-9) and one thermocouple (TC-1) located at the top of inner rod was not used. A couple of semi-cylindrical ceramic heaters with $1000 \mathrm{~mm}$ heated length encircled the channel was used to heated up the inner tube (maximum power 19.000 watt), which enable to raise up temperature of the inner tube up to $1000^{\circ} \mathrm{C}$. At the top of the test section, a water plenum (called upper plenum) made of SUS304 with capacity of 7 litters water is connected with outer tube. This plenum is heated it up by a heater (2000 watt) has been used to keep water at the upper plenum at the saturation temperature. Figure 3 shows the installation of thermocouples position and $\delta$ as a channel width.

\section{Experimental procedure}

The quenching experiments for initial temperature $650^{\circ} \mathrm{C}, \quad 750^{\circ} \mathrm{C}$, and $850^{\circ} \mathrm{C}$ were carried out successfully for channel width of $1.0 \mathrm{~mm}$ with saturation water temperature. Before the experiment, water was held in the upper plenum by a valve installed at the channel inlet. A heater was used to keep the plenum water at the decided temperature. After the inner rod was heated up to initial temperature, the heater power was switched off and the heater was removed from the heated rod. The experiment was conducted by pulling the valve open and letting saturated water fall from the upper plenum into the narrow channel in heated rod. Transient inner and outer rod temperature was measured by the thermocouples located along the outer surface of both rods. Thermocouple signals were amplified and recorded to a personal computer with a frequency of $1 \mathrm{~Hz}$ using WinDAT1000. In this experiment, the upper plenum was opened free to the atmosphere so the system pressure was atmospheric. Heat flux at the rod surface was evaluated from the temperature history of the measured point by solving the transient heat conduction problem in the inner rod. The following one dimensional heat conduction equation and boundary conditions were used. 


$$
\begin{array}{ll}
\frac{\partial T}{\partial t}=a\left(\frac{\partial^{2} T}{\partial r^{2}}+\frac{1}{r} \frac{\partial T}{\partial r}\right) \\
\frac{\partial T}{\partial r}=0 \quad \text { for } \quad r=r_{\text {in }} \\
T=T_{m} \quad \text { for } \quad r=r_{\text {out }}
\end{array}
$$

Here, $T_{\mathrm{m}}$ is the measured temperature, $a$ is the thermal diffusivity, $r_{\text {in }}$ and $r_{\text {out }}$ are inner and outer radii of the rod, respectively. The Crank-Nicolson finite difference method and tri-diagonal matrix algorism were used to solve the differential equation. This experimental result will present $\mathrm{CHF}$ by comprising for each channel width and initial temperature rod.

\section{RESULTS AND DISCUSSION}

\section{Transient temperature}

A typical transient temperature history was observed during the channel cooling process for channel width $1.0 \mathrm{~mm}$ for initial temperature respectively $650^{\circ} \mathrm{C}, \quad 750^{\circ} \mathrm{C}$, and $850^{\circ} \mathrm{C}$ for every thermocouples position (A indicate heated rod and $\mathrm{B}$ indicate outer pipe) are illustrated in Fig. 4 (a), 4 (b), and 4 (c).

Each Fig. of transient temperature shows that there is a different for cooling process between heated rod and outer pipe. Time to completely cooling for the outer pipe is faster than heated rod. Transient profile for vertical position $700 \mathrm{~mm}$ (TC-9A and TC-3B) is the same with others position, this situation was occurred due to the value of initial temperature in point $700 \mathrm{~mm}$ is always lower than $400 \mathrm{~mm}$ and $100 \mathrm{~mm}$. Characterization and calculation only performed for vertical position $100 \mathrm{~mm}$ and $400 \mathrm{~mm}$. Time to reach free convection in narrow channel will be longer for increasing initial temperature. As shown in Fig. 4 (a), Fig. 4 (b) and Fig. 4 (c), time to reach free convection for vertical position 100 and to $400 \mathrm{~mm}$ are $600-700 \mathrm{~s}$ and $900-1100 \mathrm{~s}$ for heated rod, and then $275-310 \mathrm{~s}$ and $700-800 \mathrm{~s}$ for outer pipe. Time for outer pipe is faster than heated rod, this means that heat is higher transferred to other system (outer area) at outer tube. The profile of transient temperature also shows that there is a different profile for transient temperature in single heated. In the heated rod, there are two types of decreasing pattern above rewetting point. First decrease in heated rod (still in film boiling area at the surface of heated rod) indicating a sharp decrease at transient temperature at outer pipe (transformation from transition to nucleate boiling in the surface of outer pipe). The phenomenon of bilateral heated in this experiment was showed in Fig. 5.

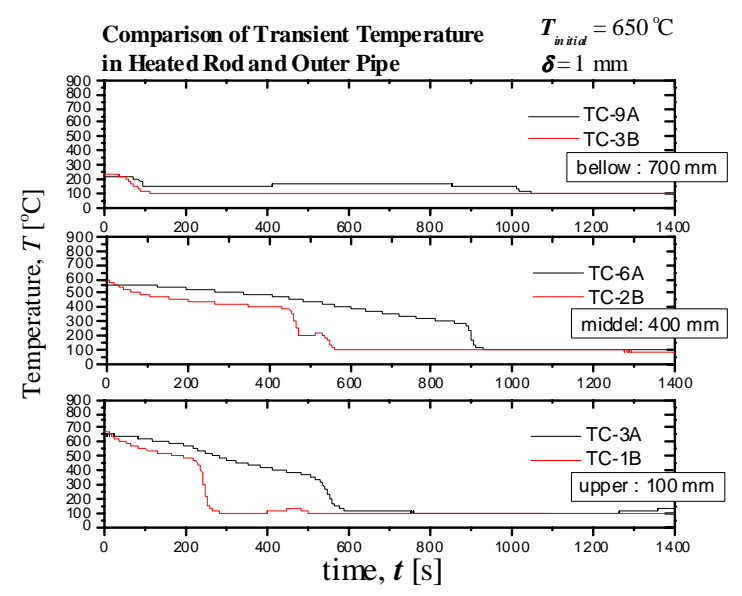

Fig. 4 (a). Transient temperature for heated rod and outer pipe at initial temperature $650^{\circ} \mathrm{C}$.

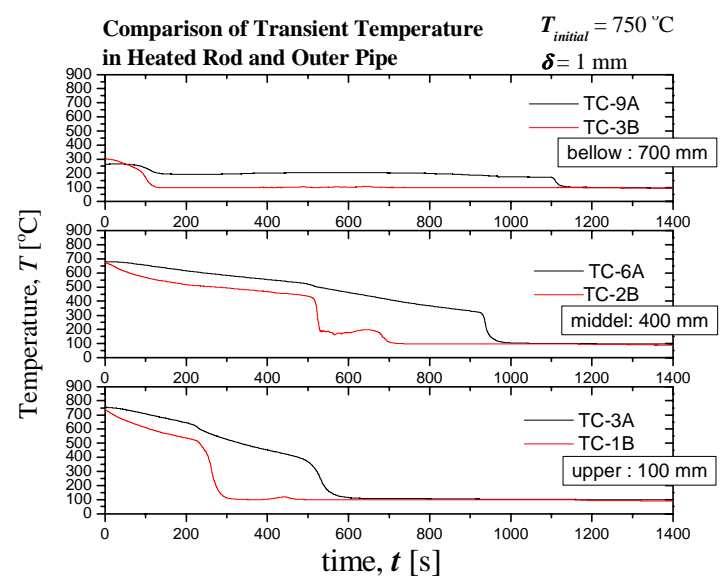

Fig. 4 (b). Transient temperature for heated rod and outer pipe at initial temperature $750^{\circ} \mathrm{C}$.

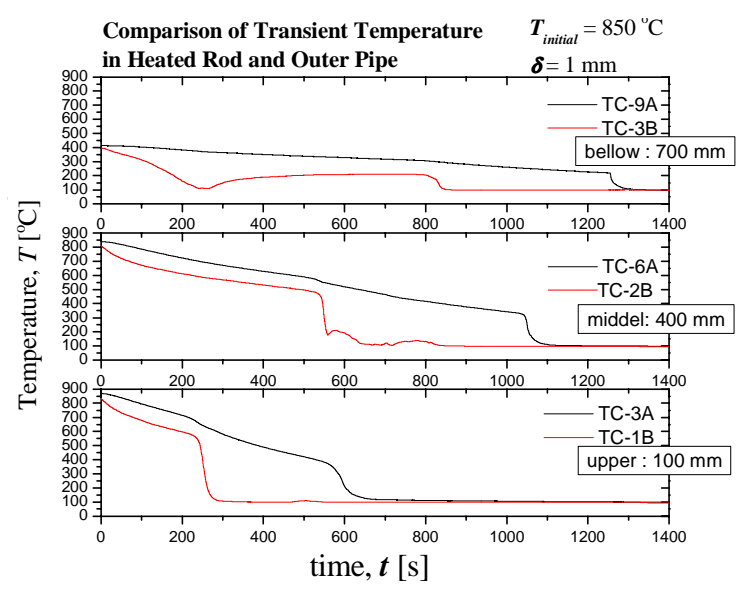

Fig. 4 (c). Transient temperature for heated rod and outer pipe at initial temperature $850^{\circ} \mathrm{C}$. 


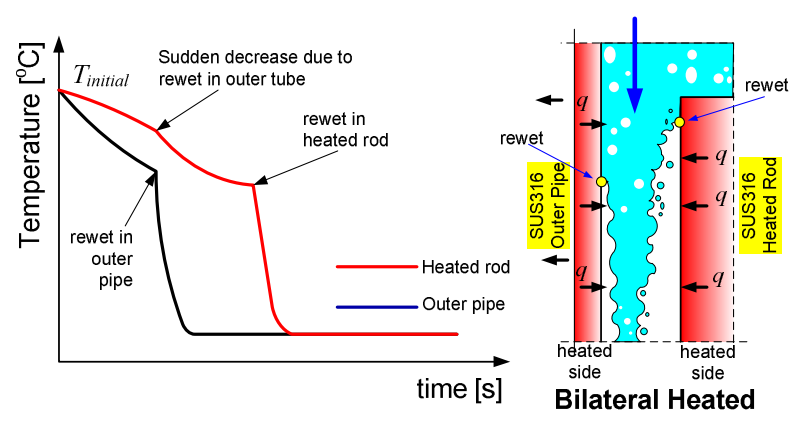

Fig. 5. Phenomena transient temperature in bilateral heated.

\section{Heat Flux}

Using the experimental data of transient temperature for vertical position $100 \mathrm{~mm}$ and $400 \mathrm{~mm}$, heat flux was calculated and pointed out as boiling curve as shown in Fig. 6(a) and 6(b). Several correlations $[7,21,22]$ were used to compare with this experimental results on boiling curve in Fig. 6(a) and 6(b) for initial temperature $650^{\circ} \mathrm{C}$, $750^{\circ} \mathrm{C}$, and $850^{\circ} \mathrm{C}$, respectively as high superheat condition. Increase of initial temperature associated with the elevation of heat removal restrictions caused by CCFL during boiling process. Almost all Fig.s of boiling curves for the film boiling region are in accordance with the Nusselt number of 4,0. Bromley correlation for pool boiling is not agreed with narrow channel cooling condition for film boiling region. The core region boiling regime, starting from film boiling (FB), transition boiling (TB), and film boiling (FB) has always been under the correlation value in the case of boiling heat transfer on the geometry of the plate, although both are in the same category in pool boiling condition. Both Fig.s show that CHF at outer pipe is always higher than at the heated rod. Also total length of FB area at outer tube was shorter than at heated rod, it is showed obviously in Fig. 5. The short period of wall superheat concerning boiling regime is transition boiling area, which related to the velocity of water penetration into the channel.

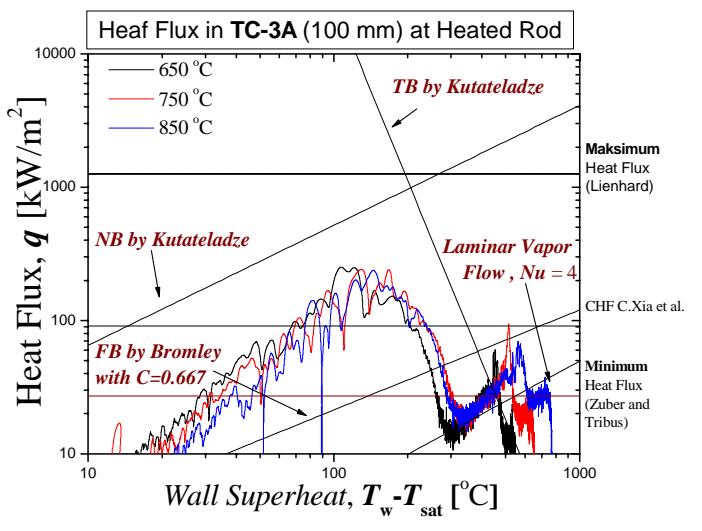

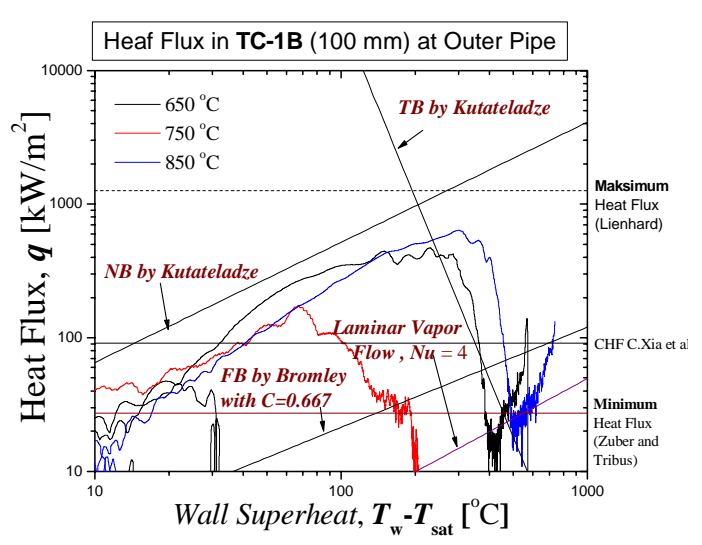

Fig. 6 (a). Comparison of Boiling Curve for Vertical Position at $100 \mathrm{~mm}$.
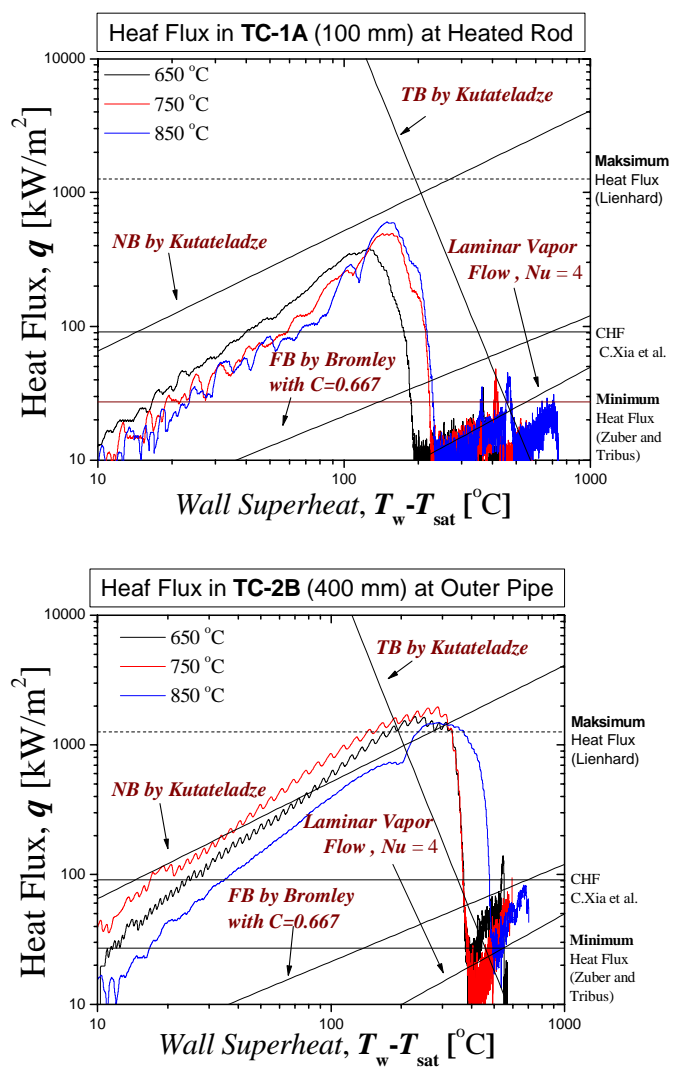

Fig. 6 (b). Comparison of Boiling Curve for Vertical Position at $400 \mathrm{~mm}$

\section{Critical Heat Flux (CHF)}

Since Fig. 6(a) and 6(b) become a famous boiling regime curve (Nukiyama, 1934), many researcher was used that boiling curve to explain several phenomena and correlation base on many variation parameters. CHF was pointed out using data from Fig. 6(a) and 6(b) into Table 1 related to vertical position and bilateral heated (outer pipe and heated rod). 
Table 1. CHF Point for Three Initial Temperature at Vertical Position $100 \mathrm{~mm}$ and $400 \mathrm{~mm}$.

\begin{tabular}{|c|c|c|c|c|c|c|c|c|}
\hline \multirow{3}{*}{$\begin{array}{c}\text { Initial } \\
\text { Temperature } \\
{\left[{ }^{\circ} \mathrm{C}\right]}\end{array}$} & \multicolumn{4}{|c|}{ Vertical Position $100 \mathrm{~mm}$} & \multicolumn{4}{|c|}{ Vertical Position $400 \mathrm{~mm}$} \\
\hline & \multicolumn{2}{|c|}{ TC-3A in Rod } & \multicolumn{2}{|c|}{ TC-1B in Pipe } & \multicolumn{2}{|c|}{ TC-6A in Rod } & \multicolumn{2}{|c|}{ TC-2B in Pipe } \\
\hline & $\begin{array}{c}\text { CHF } \\
{\left[\mathrm{kW} / \mathrm{m}^{2}\right]}\end{array}$ & $\begin{array}{c}\Delta T_{\text {wall }} \\
{\left[{ }^{\circ} \mathrm{C}\right]}\end{array}$ & $\begin{array}{c}\text { CHF } \\
{\left[\mathrm{kW} / \mathrm{m}^{2}\right]}\end{array}$ & $\begin{array}{c}\Delta T_{\text {wall }} \\
{\left[{ }^{\circ} \mathrm{C}\right]}\end{array}$ & $\begin{array}{c}\mathrm{CHF} \\
{\left[\mathrm{kW} / \mathrm{m}^{2}\right]}\end{array}$ & $\begin{array}{c}\Delta T_{\text {wall }} \\
{\left[{ }^{\circ} \mathrm{C}\right]}\end{array}$ & $\underset{\left[\mathrm{kW} / \mathrm{m}^{2}\right]}{\mathrm{CHF}}$ & $\begin{array}{l}\Delta T_{\text {well }} \\
{\left[{ }^{\circ} \mathrm{C}\right]}\end{array}$ \\
\hline 650 & 250 & 100 & 90 & 70 & 390 & 140 & 300 & 180 \\
\hline 750 & 250 & 120 & 450 & 200 & 500 & 180 & 900 & 240 \\
\hline 850 & 250 & 150 & 600 & 300 & 600 & 190 & 1000 & 300 \\
\hline
\end{tabular}

Data from Table 1 was used to make a curve to compare $\mathrm{CHF}$ and Initial Temperature. This analysis explains the connection CHF based on initial temperature changes. Figure 7 and 8 show that there a differences of CHF value and pattern between outer pipe and heated rod.

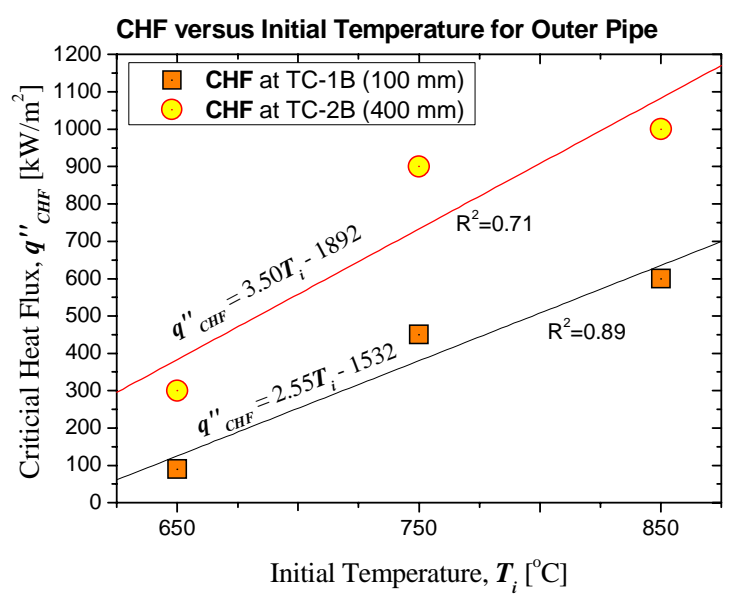

Fig. 7. CHF in Outer Pipe at $100 \mathrm{~mm}$ and $400 \mathrm{~mm}$.

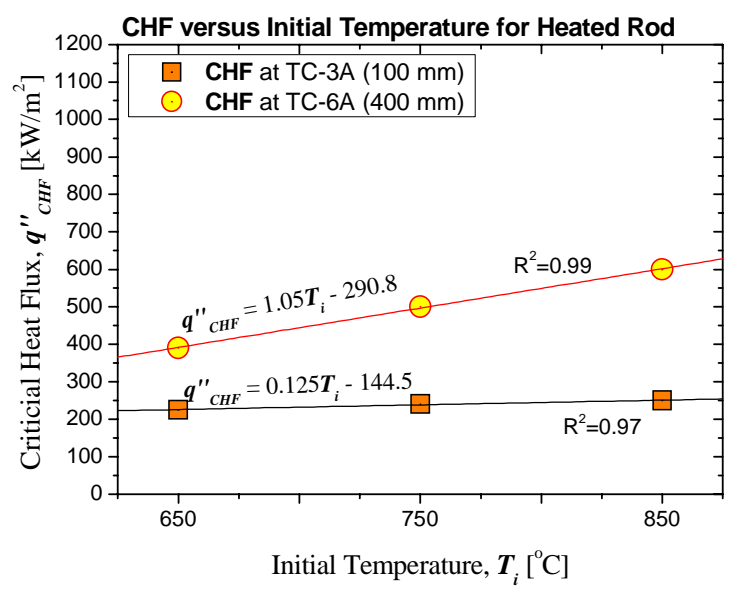

Fig. 8. CHF in Heated Rod at $100 \mathrm{~mm}$ and $400 \mathrm{~mm}$.

Figure 7 shows that linier correlation is used to approach the pattern of change in CHF against the initial temperature difference. Using a linear approach in this case shows the level of acceptance of $70 \%$ in the vertical position of $100 \mathrm{~mm}$, which could be considered poor. The vertical position of $400 \mathrm{~mm}$ is $89 \%$ is much better. The value of slope for vertical position of $100 \mathrm{~mm}$ is bigger than vertical position of $400 \mathrm{~mm}$, because the heat flux profile at upper region is higher. Contribution heat transfer which was released at outer tube occurs in two sides, first heat transferring flow inner surface into fluid (water and vapor) inside narrow annular channel and second, heat transferring into ambient from outer surface of outer pipe. CHF in significantly has changes in dramatically, as shown in Fig. 7, gradient for vertical position of $100 \mathrm{~mm}$ is 2.55 and for $400 \mathrm{~mm}$ is 3.50 .

Figure 8 also explains the effect initial temperature rise on CHF. The CHF on the heated rod at the vertical position of $100 \mathrm{~mm}$ was almost constant with the level of acceptance of linear correlation is $97 \%$. This is due to fast cooling of the top of heated rod. The condition is interesting and shows that the CHF can be said no significant change despite the increase of initial temperature with the temperature gradient of 0.125 . While in the vertical position of $400 \mathrm{~mm}$, the CHF variation with temperature could be approached by the application of linear correlation with acceptance of $99 \%$ and the temperature gradient of 1.05 .

The heat transfer mechanism at heated rod occurs only on one side, i.e. the outer surface of heated rod transfer the heat by convection into water and steam in the annular narrow channel. The involving of counter current flow also becomes one of important parameter which may affect the value of $\mathrm{CHF}$.

\section{CONCLUSION}

Experimental study to investigate the effect of initial temperature on CHF in a vertical annulus narrow channel with bilateral heated has been done to understand the complexities of boiling in the narrow channel which was occurred in a severe accident on nuclear power plant. This experimental study shows that the rewetting velocity at outer pipe is faster than the heated rod. This is affected by boiling condition inside annulus narrow channel. The fastest time for the occurrence of rewetting is 275 seconds at outer pipe and the longest time to occurrence of rewetting is 1100 seconds at the heated rod. Based on transient temperature data and corresponding calculated heat flux, there is three regime of boiling occurs in cooling process, namely film boiling, transition boiling and nucleate boiling. The length of film boiling regime for heated rod is longer than outer pipe. 
The value of $\mathrm{CHF}$ in outer pipe is higher than heated rod. The average value of CHF for each vertical position $100 \mathrm{~mm}$ and $400 \mathrm{~mm}$ at outer pipe are $380 \mathrm{~kW} / \mathrm{m}^{2}$ and $733 \mathrm{~kW} / \mathrm{m}^{2}$, and then at the heated rod are $250 \mathrm{~kW} / \mathrm{m}^{2}$ and $497 \mathrm{~kW} / \mathrm{m}^{2}$. It represents the cooling of outer wall is faster.

\section{ACKNOWLEDGEMENTS}

The authors would like to extends a sincere thanks to the personnel of thermal hydraulics experimental laboratory (Mr. Ismu, Mr. Kiswanta and Mr. Edy Sumarno) and the head of PTRKN BATAN and Incentive Research Programs FY 2007 from Ministry of Technology and Research (KRT) for fully support to conduct this research.

\section{REFERENCES}

1. TMI-2 Core damage, http://www.mpr.com/ graphics/d-d_tmi2coredamage.gif

2. Technical Staff Analysis Reports Summary, Technical Assessment Task Force Reports. http://stellar-one.com/nuclear/staff_reports/ summary_core_damage.htm.

3. E. Ishibashi and K. Nishikawa, Int. J. Heat Mass Transfer 12 (1969) 863.

4. M. Monde, H. Kusuda and H. Uehara, Transactions of the ASME 104 (1982) 300.

5. Y. Chang and S.C. Yao, Trans of ASME $\mathbf{1 0 5}$ (1983) 192.

6. H. Ohtake, Y. Koizumi and A. Takahashi, JSME 64 (624) (1998) 181.
7. M. Murase, T. Kohriyama, Y. Kawabe, T. Yoshida and Y. Okano, Proc. ICONE-9 (2001) 8 .

8. F. Tanaka, M. Juarsa and K. Mishima, Proc. ICONE-11 (2003) 36177.

9. M. Juarsa, Master Thesis, Graduate School of Energy Science, Kyoto University (2002).

10. Y. Fujita, et al., Int. J. Heat Mass Transfer 31 (2) (1988) 229.

11. J. H. Jeong, et al., SARJ-97 workshop. JAERIConf. 98 (009) (1997).

12. Y. Koizumi, H. Nishida, H. Ohtake and T. Miyashita, Proc. ITMNRT $8^{\text {th }} 1$ (1997) 48.

13. Y. Koizumi, et al., Japanese Heat Transfer Conference D221(1999).

14. A.J. Holt, B.J. Azzopardi and W.M. Biddulph, Chem. Eng. Res. 77 (1999) 7.

15. F. Fu, J.F. Klausner, Int. J. Heat Fluid Flow, 18 (1997) 541.

16. J.F. Klausner, B.T. Chao and S.L. Soo, J. Mech. Eng. Sci. 205 (1991) 317.

17. M. Fossa, C. Pisoni and L. Tagliafico, Int. Commun. Heat Mass Transfer 22 (1995) 825.

18. S.F. Sun, Y.Y. Wu and R.Y. Zhao, Cryogenics 41 (2001) 231.

19. S. Doerffer, et al., Nucl. Eng. Des. 177 (1997) 105.

20. G. Su, et al., Nucl. Eng. Des. 225 (2003) 219.

21. L.A. Bromley, Chem. Eng. Res. 46 (1950) 221.

22. C. Xia, et al., Exp. Therm. Fluid Sci. 12 (1996) 313. 